\title{
ESTATUTO CONSTITUCIONAL DE LA LIBERTAD DE INFORMACIÓN
}

\author{
José Luis Cea Egaña \\ Profesor de Derecho Constitucional \\ Pontificia Universidad Católica de Chile
}

\section{INTRODUCCIÓN}

En este ciclo de conferencias tendré el agrado de referirme a dos grandes temas. El primero es el que dice relación con las implicancias constitucionales del Estatuto de la libertad de expresión o libertad de información. Trátase del Estatuto Constitucional de la Libertad de Información. Y el segundo de los tópicos que voy a abordar es más específico, más circunscrito. Se refiere al Derecho Constitucional a la intimidad y a la honra, particularmente en ligamen a veces crispante, a veces tensionante, con el tema que vamos a abordar en la primera de las conferencias, vale decir, con el derecho a la información o con la libertad de informar, más propiamente dicho.

Efectuaré una exposición concisa, relativamente breve, con el tono coloquial de una clase más, en lugar de acudir a la lectura de las ideas que tengo preparadas, con el objeto de infundirle una mayor vivacidad a la disertación. Tras esta los invito cordialmente, a que tengan a bien formularme las preguntas que estimen pertinentes.

Es para mi una oportunidad de una actividad participativa de aquellas que se llaman interactivas. Así entiendo la labor universitaria y, por lo tanto, pido que me perdonen por no usar de ciertas formalidades y darle a la exposición el tono de charla. Naturalmente desde ya mi querida amiga, la Directora de la Escuela, Profesora Luz María Reyes, sabe que yo he prometido entregar el texto de mis conferencias y así lo haré.

Vamos, entonces, en la primera charla, de esta grata tarde, a preocuparnos del Estatuto Constitucional de la Libertad de Información. Creo que debo iniciar el tratamiento del asunto manifestando que, a pesar, como lo escuchábamos en palabras de mi amable presentador, de llevar más o menos 30 años dedicado a estudiar y a escribir sobre el tema, tengo que reconocer que hoy tengo más dudas, inquietudes, y tal vez la sensación de peligros, de riesgos, que hace 30 años o 20 años atrás. No sé si tal fenómeno es parte de la vida. Cuando el académico se dedica a estudiar algo y, yo lo he hecho también en el foro y en dictámenes o Informes en Derecho, va aprendiendo más de la realidad y convenciéndose, sin embargo, que sabe menos.

La vida es tan rica y compleja que uno termina reconociendo que es muy poco lo que ha logrado acumular de conocimiento, y menos todavía lo que ha podido absorber con una visión propia. Puede ser, y probablemente esa es una de las explicaciones de la situación que me aflige; pero puede ser también que, sensible como he sido por tanto tiempo a la temática de la libertad de expresión, a la cual se le fue con los años adicionando el problema de la intimidad, del honor y también de la vida pública, puede 
ser, digo, que mi preocupación derive de la irrupción de proyectos, de la acumulación de decisiones políticas contingentes, del desencadenamiento de una serie de sucesos en los últimos meses o años, de los cuales nosotros somos protagonistas porque los estamos viviendo.

Eso es lo hermoso de la disciplina constitucional, en la que uno va presenciando la historia y el curso presente como protagonista. Puede ser que el riesgo que percibo, el temor que siento, la angustia que me preocupa sea consecuencia de que no diviso criterios claros, ni valores definidos, ni horizontes despejados en el legislador, en los profesores, en los comunicadores sociales, en los periodistas, en los abogados ni en los alumnos. A veces y por cierto no descubro esos criterios en las autoridades especializadas en el tópico. No veo ninguno de tales atributos, con los cuales, empero, tendríamos que contar para que pudiéramos decir que el Estatuto Constitucional de la Libertad de Información, o sea, el régimen jurídico de esta libertad que es la libertad madre de la democracia, sin la cual no hay posibilidad de un régimen de Derecho y de transparencia, de responsabilidad y control, se halle garantizado con certeza frente a los acontecimientos que estamos viviendo.

¿Por qué digo esto?

En primer lugar porque Uds. comprenderán que el tema de la libertad de información o de la libertad de expresión es muy importante, trascendental en la vida de todos nosotros.

Yo estoy aquí ejerciendo mi libertad de expresión ante Uds. Un profesor hace lo mismo en su cátedra y Uds. están ejerciendo la suya al venir a esta reunión a escucharme, actitud que les agradezco de corazón.

El Intendente Regional usa de su libertad de expresión al explicar o defender tal o cual decisión de la autoridad en el ámbito de su competencia. Los medios de comunicación social son, podríamos decir, los que clásica o típicamente, disfrutan la libertad de expresión.

La libertad de expresión tiene, por lo tanto, una importancia general, ya que a todos nos llega, a todos nos hace falta, a todos nos sirve. Empero, hay acontecimientos que son los que explican la trascendencia singular que tiene en este momento el estudio de la materia, que me parece indispensable mencionar, con el objeto que Uds. se percaten de la complejidad que va adquiriendo.

\section{CONCRECIONES PRÁCTICAS}

Piensen Uds. que, en este momento, nosotros nos encontramos con que hay tres cuestiones concretas pendientes, las cuales dicen relación, precisamente, con la vida privada, la vida pública y el derecho o la libertad de información.

En primer lugar, Uds. saben que está en discusión en el Congreso Nacional, en primer trámite en la Cámara de Diputados, un proyecto de ley que establece en Chile el llamado habeas data. Trátase de normar la facultad de cualquier sujeto, por ejemplo un deudor del crédito universitario, un deudor de cualquier tienda que trabaje sobre la base del crédito, de exigir que se le entregue, por la empresa respectiva, toda la información con la cual cuenta en su base o banco de datos informatizados. El proyecto que 
se está tramitando repercute incluso en la legislación bancaria que, a su vez, se está despachando exactamente hoy en el Congreso.

Simultáneamente Uds. son testigos de que ,en estos días, el Presidente de la República ha hecho llegar al Congreso Nacional un mensaje proponiendo la abolición de la censura en Chile, para lo cual plantea derogar la disposición que la contempla en el Artículo 19 № 12 inciso final de la Constitución. En su lugar, el mensaje contempla un sistema que se denomina de Calificación en Materia de Producción Cinematográfica y su Publicidad. Supresión, abolición o erradicación de la censura previa en materia de producción cinematográfica y publicidad de la misma, acompañada de una nueva idea, que consiste en contemplar en Chile, por vez primera según el Presidente, lo que en el mensaje se denomina la libre creación y difusión de las artes. Es decir, estamos frente a una cuestión que es interesante, cual es la supresión de la censura ; y paralelamente de cara a la incorporación de la facultad de difundir y crear libremente las artes.

También Uds. son testigos que, a raíz de los acontecimientos penitenciarios ocurridos a fines del año pasado, en torno de la fuga de los reos de la Cárcel de Alta Seguridad, se inició una serie de discusiones que se ha traducido en el estudio de reformas a la legislación sobre servicios secretos en Chile.

Yo di una conferencia el Miércoles de la semana pasada, el 30 de Abril, con la ocasión del $4^{\circ}$ aniversario de vigencia de la ley que creó la Dirección de Seguridad Pública e Informaciones. Lo hice en presencia del Director de ese Servicio, Dn. Mario Papi, del Ministro del Interior, del Director General de Carabineros, y del Director General de Investigaciones. Ahí tuve la oportunidad de abordar, en líneas generales, como ciudadano, pues no trabajo en ninguna de la comisiones de estudio de esta legislación, las reformas que se quiere introducir a la normativa sobre servicios secretos. Uds. comprenderán, que servicios secretos son exactamente los que no entregan entonces información. Estamos tocando, por ende, el tema de la vida pública y del secreto de ciertas cuestiones públicas, como son las que manejan los servicios que están destinados a ese objeto en los regímenes democráticos, los cuales es importante que funcionen con eficiencia.

Por último, Uds, deben saber que hay otros asuntos que dicen relación con el tema de esta primera conferencia.

Efectivamente, antes de ayer el Senado aprobó en general una nueva Ley de Libertad de Información. Se deroga la ley que data de 1967. Ilamada Ley de Abusos de Publicidad, y se la reemplaza por otra de quórum calificado, aprobada por el Senado en segundo trámite constitucional. Y esa legislación contempla una serie de innovaciones importantes. No sé si en la audiencia se encuentra presente algún periodista, o comunicador social, pero Uds. siguieron las informaciones de los medios de comunicación pudieron comprobar que, alrededor de 200 jóvenes, promovieron tumultos en la Sala del Senado, al momento en que se votaba por la Cámara Alta esta materia, como consecuencia de que el proyecto incluye una disposición que contempla el ejercicio preferente, pero no exclusivo, de la libertad de información por los medios de comunicación social para los periodistas. Y junto con eso, en esa legislación se establece el acceso a las fuentes públicas de información; se regula el secreto profesional en materia informativa; se define una serie de disposiciones importantes, y felizmente, no se incorpora la regulación típica, jurídica e irreprochable, vale decir, el tipo penal en relación con el delito de difamación. 
Me asiste la convicción, por diversas y sólidas razones, que la difamación, es una figura punible, desterrada de los Códigos Penales modernos, porque resulta peligrosa para el ejercicio seguro, quiero decir objetivo, imparcial y confiable de la libertad de información en una sociedad democrática. Ella se presta, por el contrario, como está demostrado en todas las legislación del mundo, para que nunca falten quienes, con un sentido patológico del abuso informativo del cual serían víctimas, ejerzan acciones civiles o criminales que terminen con los periodistas en la cárcel, o con los medios de comunicación social en bancarrota por el pago de indemnizaciones cuantiosas en resarcimiento del daño moral causado

Y como si todo lo anterior fuera insuficiente para captar la importancia actual y la trascendencia del tópico que me ocupa, les puedo agregar que se encuentran en discusión dos o tres otros asuntos que también quiero mencionar.

Efectivamente, en los próximos días la Corte Suprema debe fallar en Alzada, vale decir conociendo un recurso de apelación, la sentencia dictada en el mes Enero pasado por la Corte de Apelaciones de Santiago, en relación con la proyección del filme La última tentación de Cristo. Sobre este punto no puedo dejar de mencionar que se trata de una cuestión pendiente, de la mayor importancia, respecto de la cual creo que nadie de los presentes o de los ausentes que han seguido el debate no hayan adquirido una posición de aprobación o crítica a lo fallado. La Corte Suprema está por sentenciar la apelación que está deducida y pendiente desde el 20 de Enero del presente año.

Y próximo a lo anterior, Uds. son testigos de la polémica, que el Diario "El Mercurio" hace pocos días, a mi juicio con buen criterio, calificaba en un editorial de agotada o terminada, de concluida, que se desató a raíz de la contratación que se quiso hacer por el Gobierno, el Ministerio de Salud concretamente, de ciertos espacios de transmisión publicitaria para prevenir el Sida, en el Canal de la Corporación respectiva de la Universidad Católica de Chile y en el Canal Megavisión.

A ellos se agregó el Canal de la Universidad Católica de Valparaiso, todos los cuales no han aceptado transmitir los spots que se le solicitaron por el Gobierno. Y esta situación, me parece ridícula porque resulta insostenible que a estas alturas estemos obligando a los medios de comunicación social que transmitan lo que el Gobierno decida, pero ni siquiera como autoridad, porque entonces no entiendo en qué consiste la libertad de informar.

Esta situación, de aceptarse tal predicamento ha suscitado sin embargo una serie de duros y ácidos ataques a las instituciones propietarias de dichos canales.

En resumen, estamos frente a una temática dinámica, compleja, de extraordinaria importancia para todos y cada uno de nosotros, que repercute en las personas, en las familias, en la comunidad y en el Estado en general, y respecto de la cual no creo que nadie pueda decir que le resulta indiferente o que se siente al margen de lo que está ocurriendo.

\section{SÍNTESIS DEL ESTATUTO}

En el entendido de que hemos quedado más o menos sensibilizados a captar la importancia que tiene este tema, doy un paso adelante y paso a referirme entonces a 
los aspectos más importantes del Estatuto Constitucional de la Libertad de Información.

En este punto, hay una norma que es fundamental y que se debe retener en la memoria. La norma capital es la contemplada en el Artículo 19 № 12 , inciso $1^{\circ}$ de la Constitución. Esa norma, cuyo texto y espíritu todos los chilenos y chilenas con un cierto nivel cívico tendrían que conocer y captar en sus implicancias, dice que la Constitución asegura a todas las personas la libertad de emitir opinión y de informar.

Cuando dice que asegura dichas libertades a todas las personas, quiere decir que el sujeto activo de la libertad es amplísimo, de modo que no deja a nadie excluido. Incluso el niño, en la medida en que pueda usar de sus facultades intelectuales con discernimiento, es titular del derecho referido.

Asegura la Constitución facultad de emitir opinión y la de informar. "emitir opinión y de informar" . La libertad de informar, por lo tanto, sin censura previa, en cualquier forma y por cualquier medio. $Y$ agrega "sin perjuicio de responder por los delitos y abusos cometidos en el ejercicio de esta libertad en conformidad a la ley". Puntualiza por último que esta ley será de quórum calificado, vale decir, de las que necesitan el voto de la mayoría de los Senadores y Diputados en ejercicio para ser aprobadas, modificadas o derogadas.

Esa es la norma axial, la que asegura la libertad de emitir opinión e informar sin censura previa, sin perjuicio de la responsabilidad ex post, ulterior o mal llamada represiva, y que se traduce en las querellas criminales por injurias y calumnias, vale decir aquellos procesos que demoran dos años en el mejor de los caso o que usualmente llevan a $3,4 \circ 5$ años, o que nunca reciben ninguna sentencia porque terminan en sobreseimiento o en avenimiento con perjuicio para que el ha sido injuriado o calumniado.

Pues bien, en torno de esa norma central, gira otra serie de disposiciones de la Carta Fundamental que también aseguran a todas las personas derechos públicos subjetivos, que son tanto o más importantes que la libertad de emitir opinión y la de informar.

Así es como nos encontramos, en primer lugar, con un derecho al que me voy a remitir en la segunda de la conferencias, que es el derecho a la intimidad, el derecho a la honra y el derecho a la vida pública. Pero también nos hallamos con que la libertad que se asegura en materia de expresión o información está vinculada con la libertad de conciencia.

De alguna manera, cuando Uds. ejercen su libertad de información y de expresión, exteriorizan, lo que es una vivencia en lo más íntimo de la conciencia. Es la conciencia, o sea, el lugar en donde Uds. van construyendo su identidad y su proyección en la convivencia. Tiene, por lo tanto, la libertad de expresión una relación indudable con el ejercicio de la libertad de conciencia ; y ésta es un concepto genérico que abarca, entre otros, a la libre expresión de los cultos, siempre que no se opongan a la moral, a las buenas costumbres o al orden público.

Esta norma del artículo 19, № 12, o norma central o capital como lo he dicho, se vincula en tercer y cuarto lugar, al derecho a reunirse para cumplir con un rasgo esencial y hermoso de nuestra vida en cuanto seres sociales, cual es, la de dialogar, y compartir. Se vincula, en fin, con la facultad de asociarse, vale decir, de formar asocia- 
ciones como una universidad, un ateneo, un círculo científico, una asociación económi$c a$, un ente sindical o de otra naturaleza.

\title{
III. LIBERTAD DE INFORMAR Y NO DERECHO A LA INFORMACIÓN
}

\author{
Esa libertad tiene en la Constitución, tres aspectos que tengo que realzar.
}

El primer aspecto estriba en que lo asegurado por la Constitución es la libertad de emitir opinión y la de informar. No podemos detenernos a operacionalizar la diferencia entre el concepto de opinión y el de información, pero afirmo que no son conceptos idénticos. No es lo mismo ejercer la libertad de opinar que ejercer la libertad de informar. Cuando yo soy director de un diario, revista o periódico y escribo un editorial, como en el periódico de esta ciudad "El Día", ese editorial forma parte de lo que se llama el periodismo de opinión. A través de él se fija su línea editorial. Pero si en el diario leo, que mañana llega el Senador Piñera o que pasado mañana clausuran el Congreso Nacional de Alcaldes en La Serena, se está informando y no juzgando u opinando. La información, por lo tanto, es la transmisión de mensajes sobre hechos, sobre acontecimientos nacionales o extranjeros, sean históricos, del presente o del futuro. como es el que cultivan las personas dedicadas a la futurología.

La Constitución asegura ambas libertades: La libertad de emitir opinión, -la opinión por definición es un juicio intermedio entre la certeza y la ignorancia; y la libertad de informar, vale decir de transmitir mensajes sobre acontecimientos o de hechos que se llaman noticias del acontecer nacional o internacional.

¿A dónde quiero llegar yo con este primer punto o con esta precisión inicial sobre el Estatuto Constitucional que estoy explicando? Quiero que Uds. comprendan con claridad, con certeza, que la Constitución no asegura, que la Constitución no reconoce, y que por lo tanto tampoco ella permite que se sostenga que existe en Chile el Derecho a la Información. La Comisión que redactó este texto de la Carta Fundamental, presidida por el señor Ortúzar, en una primera versión quiso incorporar el derecho a la información como un concepto distinto de la libertad de informar o de informarse y de la libertad de emitir opinión, y entonces durante el debate quedó constancia, -eran actas prolijas- que un comisionado preguntó ¿Y quién sería el titular de este derecho a la información? y entonces se le respondió: La comunidad. Y continuando el diálogo, quien preguntaba inquirió a su vez ¿Y quién es la comunidad? Somos todos dijo, o somos todos y cada uno. Entonces se le responde: "Ahh... es que entonces interviene el Estado en representación de la comunidad. (...) Quiere decir entonces que, en definitiva, terminamos en que el titular del derecho a exigir información es el Estado". En ese mismo momento, añado yo, hemos entrado en un sistema que no es democrático, en el colectivismo, porque lo primero que va a exigir el Estado, es que se informe de lo que él ordena en el nombre siempre del bien común, porque Uds. comprenderán que el Estado nunca va a dejar de invocarlo. Sería necia una autoridad política si alegara que no lo hace en aras del bien común.

Como se percibieron allá por el año 74 en ese debate de la Comisión de Estudio, las implicancias que tenía para un régimen democrático, para un Estado de Derecho, contemplar el derecho a la información como un concepto distinto de la libertad de informar y de opinar, se cambió el criterio de la comisión, se eliminó este derecho y se 
dijo que lo garantizado es la libertad de informar pero no el derecho a exigir la entrega de información.

Y Uds. deben seguir mi raciocinio para concluir que es distinto, muy distinto que el director de un diario, el rector de una universidad, el intendente regional, el presidente de una asociación gremial, un Ministro de Estado o un gerente de empresa, entregue información, incluso a la opinión pública, a que, por otra parte, cualquier persona, sea periodista o no, llegue ante la autoridad y muchas otras personalidades y les diga: "Señor Ud. me entrega toda la información que yo quiero, incluso la que pudiéramos decir es de datos sensibles, reservados o secretos, porque tengo derecho a acceder a ella o yo deduzco un recurso de protección en su contra". A eso se puede llegar con el derecho a la información. Él se transforma - o puede convertirse- en un arma de potencialidad incalculable, incluso lindante con el chantaje o la extorsión.

Por eso es que en ninguna legislación democrática del mundo, con regímenes político-jurídicos consolidados y de carácter pluralista, está reconocido el derecho a la información en los términos que estoy mencionando. Lo que se consagra en los tratados internacionales sobre derechos humanos es la libertad de informar, que es distinto. Y esta conclusión no es algo elaborado a solas, una mera opinión mía.

Lo que estoy diciéndoles, es el criterio manifestado por el Tribunal Constitucional de Chile en su sentencia del 30 de Octubre de 1995, cuando el considerando $12^{\circ}$ dijo: "que si bien el Tribunal acepta que la disposición requerida (se refiere al proyecto de ley de libertad de información que antes de ayer despachó el Senado) no atenta contra el texto constitucional, debe señalar que lo hace solamente en el entendido que el derecho (contestado al derecho a la información previsto en el proyecto) establecido en el para que las personas reciban información (derecho a la información) se refiere a que después de proporcionadas por lo medios de comunicación, nace ese derecho". Después de proporcionadas las informaciones por lo medios nace el derecho a la información. Y agrega, para precaver cualquier vacilación o duda, que ello no significa, en ningún caso, que el legislador puede obligar a alguna persona o institución o algún medio a entregar determinadas informaciones. Si así fuere y se entendiera que la autoridad puede obligar a las personas, -por ejemplo en el caso de los spots del sida-, o a los medios a informar, se estaría atentando contra claros preceptos constitucionales, como son la autonomía de los grupos o de las instituciones y la libertad de opinar e informar sin censura previa.

De manera que, cerrando este primer aspecto de la norma fundamental del Artículo 19 № 12, espero que les haya quedado claro cuál es el sentido y alcance que tiene la libertad de emitir opinión e informar, y sobre todo, excluir que en estas palabras "libertad de emitir opinión e informar" esté involucrado el derecho, coactivamente exigible, compulsivamente demandable sobre cualquiera de Uds. o sobre cualquier medio de comunicación social, o autoridad, para que entregue la información que el requirente estime adecuada, conveniente o necesaria a los designios que él mismo califique.

\section{PUNTUALIZACIÓN SOBRE CENSURA}

Llegamos así al segundo de los tres puntos sobre los cuales quiero hacer hincapié. Recordarán que al leer la disposición fundamental ya explicada, insistí en que la 
libertad de emitir opinión e informar se ejerce según la Constitución, o está garantizado que se pueda ejercer, sin censura previa.

Quiero, en consecuencia, detenerme en este punto no sin antes confesarles que esta mañana,mientras preparaba, una vez más, las ideas que les estoy exponiendo, me propuse hacer un inventario de problemas vinculados con la censura, vale decir, tratar de ordenar mi mente para saber cuantos problemas yo podría plantearles con el objeto de incentivarlos a que piensen en el asunto, iy llegué a 60 !.

Naturalmente, no me voy a detener en tan extenso catálogo de problemas. A lo más escogeré tres o cuatro, que los voy a exponer para que capten la riqueza que tienen, y por lo tanto, la complejidad que encierran estas materias.

Por eso es que recordando palabras que me gusta pronunciar, los temas de la censura y de la libertad de expresión constituyen una de las que Aristóteles llamaba aporía, por ser una cuestión tan difícil de poder asir, aclarar, que nunca más se nos escape y ni presente nuevas dificultades o encrucijadas, que resulta prácticamente imposible dominar. Eso es parte de la riqueza que tiene la vida, que es muchísimo más variada que las norma jurídicas.

Pues bien, la Constitución dice que nos garantiza esas libertades sin censura previa.

Desde que era joven y me enseñaba estas materias mi maestro Alejandro Silva Bascuñán, y después cuando ya no era tan joven y ya he llegado a la adultez avanzada, me he preocupado porque siempre se alude a la censura para proscribirla, como algo execrable, abominable, ilegítimo per sé. Pero me preguntaba y voy a razonar en voz alta ¿qué es censura previa?

A veces plantearse las preguntas más simples obliga a los esfuerzos mayores para responderlas, porque posee sabiduría el dicho, según el cual "Las cosas por sabidas se callan y por calladas se olvidan".

En Chile muchos hablamos de censura previa, todos para condenarla, Pero les debo decir que nunca he encontrado en Chile y tampoco en la literatura de Derecho y doctrina extranjera, ninguna definición de censura, que no sea la que hallamos al abrir el Diccionario de la Real Academia y buscar su sentido natural y obvio.

Uds. comprenden que una cuestión de tanta importancia, de tal envergadura en la vida como es garantizar la esencia de libertades definitorias de un régimen democrático y de un Estado de Derecho, hace muchísimos años que nos tendría que haber obligado a elaborar definiciones o conceptos, con los cuales saber, a ciencia cierta, qué es y qué no es la censura previa.

¿Por qué digo ésto? Porque ayer, mientras venía en vuelo a La Serena se me distribuyó en la aeronave un ejemplar del Diario "La Época", y revisándolo me encontré un artículo que se llama "Opinión", o sea juicio intermedio entre la certeza y la ignorancia, dado por una persona que es ni más ni menos que Dn. José Joaquín Brunner Ried, Ministro Secretario General de Gobierno. Evidentemente, él es un experto en materia de comunicación social. Y leí ese artículo que se denomina La Censura y la Información. $Y$ entonces me encuentro con las siguientes preguntas las cuales se las transmito para que cada uno de Uds. trate de responderlas. Yo siento afecto y respeto por el Ministro porque soy amigo de juventud en la Facultad de Derecho de la 
Universidad Católica. Pero debo decir que con muchos de los argumentos que él ha sostenido últimamente, no estoy de acuerdo. Con respeto, por lo tanto, y en el ejercicio de mi libertad de opinión también ante Uds., leo lo que se dice en la página 10 del Diario "La Época" de ayer.

"De hecho en un sistema de mercado -como el chileno podríamos decir, agregándolo yo- con pocas empresas informativas" -aquí donde entonces uno dice a ver, claro estoy ubicándome entre los diarios y de ellos, cuáles pueden ser esas pocas empresas; entre los canales de televisión ocurre lo mismo; en materia de radiodifusión diría que es más desperdigado el asunto, porque la gama sobrepasa las 500 radioemisoras en el país; pero en definitiva, uno entonces comienza, a percatarse adonde apunta el argumento. "En un sistema de mercado con pocas empresas informativas de alcance nacional, el ámbito más extenso de riesgo para la libre información reside seguramente en el comportamiento de las propias empresas" - el Ministro está escribiendo a propósito de la censura, no olviden-, y agrega :

"¿Cómo llamar, por ejemplo, al acto hipotético, pero que podría ocurrir en la práctica, mediante el cual un canal de televisión decidiera no poner nunca en pantalla a un determinado político relevante?" ; y responde él mismo más adelante : "Lisa y llanamente eso es censura" del canal.

Y nos propone un segundo ejemplo: "¿Cómo llamar a la actitud de un diario que consistentemente se negara a informar sobre las actividades de un determinado partido político o de una iglesia.?". Y él contesta: "Lisa y llanamente eso es censura".

Y agrega un tercer ejemplo: "¿Cómo llamar a la decisión de una industria cinematográfica de no contratar jamás a una persona que por motivos ideológicos hubiese sido puesta en una cierta lista negra?". Y termina diciendo: "¿Cómo llamar a estas acciones? sino lisa y llanamente -ya lo dije- censura".

Yo subrayé eso pensando en Uds. y dije: No, yo creo que eso no es censura. Eso es ejercicio de la libertad de informar, porque si eso es censura, entonces, ahí fue donde llegué hoy día a reunir 60 casos. Creo que la lista sería susceptible de prolongarse muchísimo más, de ejemplos que, a diario, casi de manera insignificante en nuestra convivencia, nosotros podríamos decir: ¡Ahh... que entonces también esto es censura!.

\section{SITUACIONES INCONFUNDIBLES}

Cuando el padre le dice al niño: "No hagas ésto", porque lo quiere educar, le quiere infundir o inculcar valores, ¿lo está censurando?, como se sostiene por ejemplo en las escuelas primarias de Estados Unidos, en que en virtud del llamado political incorrectment approach los profesores no pueden mantener la disciplina en las salas, porque violentan al niño ¿es censura respecto del niño? ¿o es educarlo? Cuando en un consejo universitario se dice, "Por favor, a la salida no le transmitan los acuerdos a los periodistas con el objeto de mantener esto en un clima de reserva para no hacer fracasar las diligencias". ¿Es éso censura o es prudencia, es tino, o buen criterio?

¿Es censura que la autoridad del Estado, el Ministro del Interior, o el Subsecretario del Interior, o el General Director de Carabineros, o el Presidente del Consejo de Defensa del Estado o la autoridad que sea del orden o de la seguridad pública no entregue detalles comprometedores respecto de los operativos que se están realizando para 
detener a los involucrados en narcotráfico, o en lavado de dinero, o en procedimientos que están destinados a prevenir el terrorismo? Que no se entregue esa información ¿es censura?

Si un periódico no publica una carta que, más allá de ir en contra de su línea editorial, formula juicios aventurados sobre personas o acerca de hechos ¿incurre en censura? Vuelvo, en resumen, a plantear la pregunta ¿Qué es censura? y a plantear lo que fue la inquietud mía. Yo les decía que hace ya 25 ó 30 años, y que renuevo aquí -con aplauso a las palabras del Ministro- cuando se refiere al problema y dice que él está por un esfuerzo orientado a obtener que se haga un estudio acucioso de esta materia para aclararla. Yo creo que en eso el Ministro tiene toda la razón, pues sólo una actitud exigente del público incentiva a los medios a garantizar la libre circulación de ideas e informaciones $y$, en definitiva, a que haya un compromiso en aras de llegar a una clarificación de estos conceptos.

Pero yo no puedo decir, no puedo plantear la pregunta ¿qué es censura? sin darles un concepto.

Creo haberlos sensibilizado al problema, pero ahora tengo que asumir la responsabilidad para cerrar este segundo punto. Debo darles una definición de lo que es censura.

En un trabajo que publiqué en la Revista Chilena de Derecho, en el Volumen XX, Tomo I., del año 1993, y que se denomina Función Cautelar de la Justicia Constitucional yo definí la censura, y esa definición de censura, les digo modestamente, es la única que conozco en el Derecho chileno hasta la fecha. Por cierto estoy consciente de que es un ensayo o un intento por llegar a clarificar un concepto que requiere de precisión, pero sería una persona feliz de saber que se construyen conceptos mejores o que demuestren los errores en que yo incurrí al acuñarlo. Aquí no bastan las meras afirmaciones ni menos las descalificaciones frívolas.

Esa definición sin embargo, fue recogida por la Corte de Apelaciones de Santiago en una sentencia que dictó el 30 de Mayo de 1993, y confirmada, aunque sin referencia al considerando respectivo, por la Corte Suprema en otra sentencia que dictó el 15 de Junio de ese mismo año.

En los últimos meses ha sido nuevamente, aunque en forma incompleta y por desgracia imprecisa e inexacta, citada la definición en el Considerando № 14 de la sentencia a la cual hice referencia, es decir, del 20 de Enero de este año, recaída en la proyección del filme La última tentación de Cristo. Pero reitero que, la cita efectuada por la unanimidad de los Ministros de la Sala de la Corte de Santiago, en el Considerando 14 es incompleta, $y$, por lo tanto, inductiva a malas interpretaciones y errores. Es una lástima que en ese tipo de cuestiones tan importantes no se tenga un cuidado especial. Pero en todo caso ahí se transcribe la definición que les leo, para que por lo menos en mi exposición no se pueda decir que no di un concepto de censura.

\section{DEFINICIONES}

La censura yo la entiendo como "todo procedimiento impeditivo que forma parte de una política estatal aplicada de antemano por funcionarios públicos en general" -pueden ser funcionarios administrativos, pueden ser jueces, o autoridades políticas 
- "Todo procedimiento impeditivo que forma parte de una política estatal aplicada de antemano por funcionarios vigilantes". La censura es evidentemente contraria a la democracia, siempre incompatible con ella, dirigida a que las ideas no lleguen libremente al público por motivos religiosos o políticos, a raíz de reputarse esas ideas peligrosas para el control de la sociedad por los gobernantes o contrarios a los intereses de éstos".

Con todos los bemoles que Uds, podrán atribuirle a la definición que les he leído, repito la única que yo conozco, ha sido recogida en tres sentencias de los tribunales chilenos y no ha dado lugar a que nadie hasta el momento, que yo sepa, haya construido una definición distinta o como yo espero, mejor. Es una tarea pendiente por lo tanto.

\section{LÍMITES Y EXCEPCIONES LEGÍTIMAS}

Más todavía, he seguido preocupado del tema y en otras monografías he definido la censura como "todo impedimento ilegítimo al ejercicio de la libertad de información". Con ello queda claro que hay límites y excepciones a dicha libertad que son legítimas y no configurativas de censura.

Pero yo junto con decir esto, y como prometía con el objeto de ir cerrando estas ideas de la conferencia, digo que hay un tercer aspecto en el cual tengo que hacer hincapié. Se refiere a que no todo impedimento a la libre expresión de ideas, es constitutivo de censura.

Nosotros también estamos hechos para vivir según un orden social, respetándolo y promoviéndolo. Si Uds. captan lo que implica la idea de orden en la sociedad, de certeza o seguridad jurídica en una sociedad, podrán también comprender que la idea del Derecho, del sistema jurídico como un elenco coherente de normas coactivamente exigibles o coercitivamente imponibles, reposa sobre la base de que hay muchas conductas que están prohibidas y que no por el hecho de estar prohibidas son denotativas de censura.

El Derecho Penal, por ejemplo, sería una sucesión interminable de censuras, si acaso Uds. le dieran a la palabra censura un alcance ilimitado. Por eso es que insisto, en esta segunda idea : Hay necesidad de definir la censura, pero también de clarificar muchas prohibiciones o restricciones que son legítimas y no indicativas de censura. Son parte de un orden social respetuoso del prójimo y de la autoridad y eso no es censura.

\section{EL RÉGIMEN CHILENO}

Evidentemente cuando en la Constitución se dice que ella garantiza la libertad de emitir opinión e informar sin censura previa, y establece "sin perjuicio de responder por los delitos y abusos cometidos en el ejercicio de esta libertad", surge entonces otra idea, que es importante, aunque sea breve el comentario que haré de ella.

Se ha dicho que la Constitución chilena, y en esto no hay ninguna novedad, no hay ninguna idea que sea original de nuestro constituyente porque existe en todas partes del mundo civilizado lo mismo, se ha dicho que el sistema chileno es entonces un sistema represivo, que uno puede ejercer su libertad de emitir opinión e informar, pero 
que ello no obsta a que con posterioridad se persiga la responsabilidad penal, civil, administrativa, ministerial, laboral, cual sea, a que haya lugar por las opiniones o informaciones emitidas. Ese sistema como digo se llama represivo, y ya adelanté unos minutos antes, es un grave error llamarlo represivo porque en realidad no se reprime a nadie, más propio sería llamarlo un sistema de responsabilidad ex post, o que se ejerce la responsabilidad después de haber disfrutado del derecho. Este tipo de responsabilidad ex post o ulterior al desempeño del derecho, o al ejercicio del derecho mal llamado represión en Chile, me lleva a plantear una alternativa que yo creo que, sobre todo mirando a Profesores de Filosofía del Derecho o Introducción al Derecho, les puede resultar especialmente a ellos interesante continuar explorando.

Creo, estimados amigos, fervientemente en los Derechos Humanos. Creo que todos los derechos humanos son indispensables para que todos y cada uno de nosotros pueda desarrollar una vida digna del ser humano. Creo fervientemente que si no se respetan todos y cada uno de nuestros derechos humanos, nuestro paso por la vida no deja ninguna impronta o huella que sea propia, característica, o un sello personalísimo de nuestra existencia humana. Sería un pasar por la vida sin dejar nada sembrado, nada construido, nada hecho, elementos todos éstos que son la vocación de nuestra vida. Formar una familia, procrear, tener hijos, o si no tenemos la gracia de Dios de hacerlo así, -yo felizmente la he tenido-, por lo menos producir otros frutos.

Creo fervientemente en los derechos humanos por lo tanto, creo en la necesidad de una cultura de los derechos humanos, pero creo que los derechos humanos tienen ser siempre promovidos y respetados en su integridad. No creo en otras palabras, que existan derechos humanos que siempre deben ser respetados y otros que de vez en cuando, en términos que podríamos llamar relativos, de ocasión o de circunstancia o de oportunidad, los respetamos más o menos según sean las conveniencias del momento. Ese relativismo es fatal, porque los derechos humanos o son respetados en su integridad, comenzando con el derecho a la vida y a la integridad física y síquica de la persona, y avanzando, no es cierto, a la libertad personal, al derecho a propiedad, etc., o no son respetados en definitiva ninguno de ellos, porque uno nunca sabe donde terminan las violaciones a los derechos humanos, pero generalmente se refieren también a lo más sagrado de ellos.

¿Por qué digo esto? ¿Por qué hago este llamado a comprometerse con todos y cada uno de los derechos humanos?

Porque, sin perjuicio del examen más exhaustivo que vamos a efectuar en la segunda de las conferencias de esta tarde al referirnos a la intimidad y al honor, hay aquí una colisión, un choque, que en mi concepto es aparente y no real, entre ciertos derechos humanos, como es el derecho a la información o más bien, la libertad de informar, por una parte, y otros derechos humanos muy importantes como la libertad de conciencia, la libertad de culto, la intimidad, el honor, etc.

Creo que los derechos humanos tienen que ser respetados en su integridad, y por lo tanto, al momento de un tribunal de justicia pronunciarse respecto de ellos, su esfuerzo tiene que consistir y también en el de los abogados, en demostrarle al tribunal que es posible compatibilizarlos, conjugarlos todos. ¿Y cómo se conjugan, cómo se armonizan o se compatibilizan los derechos humanos entre sí, yendo más allá de los conflictos o colisiones que parecen insolubles? Sobre la base, respondo, de que todos los derechos humanos por muy importantes que sean tienen en definitiva un carácter 
relativo. Ni siquiera el derecho a la vida es un derecho absoluto, porque se puede invocar siempre y en cualquiera circunstancia, como sería por ejemplo cuando la Patria demanda en un guerra que vayan, los jóvenes especialmente, a defenderla. No existen derechos humanos absolutos. Si los derechos humanos fueran absolutos, y todos tuvieran ese carácter llegaríamos exactamente al postulado de Russeau, Uds. saben, Jacques Russeau, en virtud del cual cada uno de nosotros es dueño de hacer lo que se le antoje, y si eso es así, quiere decir que entonces el Derecho no puede existir y la sociedad se destruye, porque quiere decir también que es el campo de la anarquía. Que cada uno puede hacer lo que se le antoja, y no hay autoridad que les pueda imponer límites a lo que se le antoje, entonces quiere decir que ni la autoridad tiene objeto ni la sociedad se justifica.

Uds. comprenden que eso es absurdo. No estamos hechos para vivir en tales condiciones sino para esforzarnos por llegar a una convivencia civilizada. Hay que conjugar y coordinar los derechos fundamentales.

¿Pero qué sucede más allá de cualquier discurso de conveniencia, de toda palabra destinada a ganarme el apoyo de una audiencia?. ¿Qué sucede si, en definitiva, no se pueden armonizar los derechos humanos en casos concretos? ¿Si no se pueden compatibilizar los derechos humanos en tales circunstancias.?

Creo que en ese caso, después de haber hecho el esfuerzo sincero y a fondo que ya propuse, yo creo que hay que reconocer que existe una cierta jerarquización de los derechos humanos. Comenzando por el derecho a la vida y a la integridad física y síquica, y entonces habrá que reconocer que todos los temas de los derechos humanos, por muy importantes que sean, y que hay que tratar siempre de respetarlos y en todo momento, en un caso insoluble, de insuperable conflicto o colisión, me parece a mí que en términos prácticos, como lo hizo la Corte Suprema en esa sentencia del 30 de Junio del año 1993, hay que llegar a la aplicación preferente de ciertos derechos que se consideren más nucleares, más íntimos, más fundamentales como sería, lo vamos explicar en la próxima clase o exposición, como sería exactamente el derecho a la intimidad o sobre la libertad de informar. Pero es ahí donde yo creo que aparece la idea que yo quisiera que sobre todo fuera bien recibida por los Profesores de Introducción al Derecho o de Filosofía del Derecho, o a quienes le interesan este tipo de tópicos en las Escuelas de Derecho.

He dicho incesantemente esta tarde, y estas son las últimas palabras de la primera conferencia, que tenemos que comprender que no todo impedimento a la libertad de informar es censura. Hay muchas conductas de nuestra vida que son propias de una sociedad ordenada y el orden no significa censura sino que significa cultura, esa es la idea, no es censura sino que cultura, y la cultura nos impone muchos límites, que nos tomamos, no es cierto, cuando somos cultivados, y eso significa cultura, lo tomamos como algo natural, para que la convivencia sea más grata, más segura y podamos así también progresar en la comunidad.

\section{CONCLUSIÓN}

No todo impedimento es censura. Hay muchos otros elementos que son restricciones fruto del orden y de la seguridad en la colectividad, yo llego a la siguiente idea final. Yo creo que el futuro en esta materia, el futuro del Estatuto Constitucional de la 
libertad de información, de la censura, de la regulación legal del mismo, se halla fundamentalmente en torno a trabajar tres ideas, y que resumo a continuación.

La primera, hacer un esfuerzo grande, y estoy pensando sobre todo en los jueces y los Profesores de Derecho, en torno de definiciones conceptuales indispensables para entender los términos que hemos mencionado. Una tarea de clarificación epistemológica o conceptual es indispensable e impostergable para aclarar las cosas y dar punto final, por igual, a la demagogia y al autoritarismo.

Lo segundo: estoy convencido que no es conveniente, incluso creo más, creo que es inconveniente que el legislador o incluso el constituyente, no solamente por lo tanto la ley sino que la norma constitucional, se vayan dictando reforma tras reforma con textos cada vez más largos, complejos, prolijos, tratando de abarcar todas las hipótesis posibles. Los anglosajones que son los maestros en estas materias, los norteamericanos, los ingleses, los canadienses o australianos, Uds. saben que tiene legislaciones muy breves, muy escuetas y le dan justamente un gran campo vivificante, estimulante, a la jurisprudencia, a la intervención de los abogados ante los jueces y en el buen criterio de los jueces justamente al aplicar esos principios generales de la legislación o de la Constitución para ir construyendo un corpus jurisprudencial.

Creo, entonces, que no es bueno que se legisle, y se legisle, y se legisle o que se vaya modificando la Constitución para agregar esto que mencioné al pasar al comenzar, no es cierto, que nos van a garantizar la libre creación artística, ipero si ya está la libertad de expresión, pues!. Si escribo una poesía o pinto un cuadro es una libre expresión artística en la medida que sea arte, porque de lo contrario vamos a tener que definir en la Constitución o en la ley qué entendemos por arte, y no van a faltar entonces las controversias. Creo más bien que la legislación y la Constitución tienen que ser de grandes principios, de claros principios, de certeros principios en la materia, como dije, para dejar campo a la jurisprudencia.

Pero llegado al tema de la jurisprudencia -y allí es donde yo creo que está la cuestión más importante-, estimo que están comenzando a abrirse en el campo del Derecho y en la conciencia de la sociedad, las vertientes, que me lleva a esperar que se encoja el Derecho Penal y se expanda el derecho constitucional. Que se achique la última ratio que es castigar con la cárcel y, en cambio, que se expanda la intervención de los jueces para de manera preventiva, ante amenazas claras, ostensibles, actuales y patentes, de manera preventiva y no punitiva, como lo propio del Derecho Penal, puedan proteger los derechos humanos.

$Y$ entonces, si es así y no estoy equivocado; si los jueces en este ejercicio preventivo de defensa de derechos humanos, comenzando por la vida o la integridad ś́quica o física actúan preventivamente para evitar que se consume un daño irreparable, que siempre va a ser por lo tanto motivo de rencor, de violencia, de disgusto, o de crítica del orden existente, si así actúan los tribunales, yo creo que hay dos consecuencias: la primera, que Uds. comprenderán que el Derecho Penal va cediendo lugar a esta fase preventiva que es mucho más eficaz que el ordenamiento jurídico; y segunda consecuencia, y en relación a lo que hemos dicho esta tarde, allí no habrá censura, allí habrá defensa de los derechos humanos fundamentales. 